\title{
CONTROLE DA LAGARTA-DA-SOJA COM APLICACÕES DE SEU VÍRUS DE POLIEDROSE NUCLEAR POR VIAS AÉREA E TERRESTRE ${ }^{1}$
}

\author{
SÉRGIO ARCE GOMEZ² e DÉCIO LUIZGAZZONI
}

\begin{abstract}
RESUMO - De 1983 a 1988 foram conduzidos, na região de Dourados, MS, seis experimentos e três campos-piloto, objetivando controlar a lagarta Anticarsia gemmatalis Hübner, 1818, com aplicações aérea e terrestre de seu vírus de poliedrose nuclear (VPN Ag). Cem lagartas equivalentes (LE) de VPN Ag associadas a óleo de soja, melaço de cana-de-açúcar e água, foram aplicadas com avião agrícola equipado com Micronair. Os preparados oleosos (5,5 e $\left.5 \mathrm{~L} \mathrm{ha}^{-1}\right)$ e com melaço (10 $\left.\mathrm{L} \mathrm{ha}^{-1}\right)$ controlaram $75-89 \%$ e $79-96 \%$ das lagartas, respectivamente. A suspensão aquosa de $3 \mathrm{~L} \mathrm{ha}^{-1}$ foi ineficaz, porém as de 15,20 e $25 \mathrm{~L} \mathrm{ha}^{-1}$ controlaram de $81 \%$ a $90 \%$ das lagartas. Cinqüenta LE, aplicadas com avião agrícola (3 $\mathrm{L} \mathrm{ha}^{-1}$ ) ou atomizador $\left(15 \mathrm{~L} \mathrm{ha}^{-1}\right)$, foram ineficientes. Aplicações da mesma dose com pulverizador de barra (134 e $150 \mathrm{~L} \mathrm{ha}^{-1}$ ) proporcionaram controle de $87 \%$ e $90 \%$, respectivamente, e com avião $\left(15,20\right.$ e $\left.25 \mathrm{~L} \mathrm{ha}^{-1}\right)$, entre $93 \%$ e $98 \%$. Aplicações aéreas de $50 \mathrm{LE}$ com óleo de soja $\left(5 \mathrm{~L} \mathrm{ha}^{-1}\right)$ ou melaço $\left(10 \mathrm{~L} \mathrm{ha}^{-1}\right)$ foram eficientes (86-88\% e 99\%, respectivamente). Aplicações aéreas de suspensões aquosas e formulado oleoso, em campos-piloto, confirmaram os resultados experimentais.
\end{abstract}

Termos para indexação: cultura de soja, Lepidoptera, Noctuidae, Anticarsia gemmatalis, óleo de soja, melaço de cana-de-açúcar, atomizador, Micronair.

\section{CONTROL OF THE VELVETBEAN CATERPILLAR THROUGH AIR AND LAND APPLICATIONS OF ITS NUCLEAR POLYHEDROSIS VIRUS}

\begin{abstract}
From 1983 to 1988 six experiments and three pilot fields were carried out at Dourados, Mato Grosso do Sul State, Brazil, aimed at controlling Anticarsia gemmatalis Hübner, 1818 (Lepidoptera: Noctuidae) larvae through air and land applications of its nuclear polyhedrosis virus (Ag NPV). One hundred larval equivalents (LE) of NPV were applied, with soybean oil, sugar cane molasses and water, with an Ipanema spraying plane equipped with Micronair nozzles. The oil (5.5 and $5 \mathrm{~L} \mathrm{ha}^{-1}$ ) and molasses $\left(10 \mathrm{~L} \mathrm{ha}^{-1}\right)$ preparations yielded $75-89 \%$ and $79-96 \%$ control, respectively. The use of aqueous formulation $\left(3 \mathrm{~L} \mathrm{ha}^{-1}\right)$ didn't provide good control, but 15, 20 and $25 \mathrm{~L} \mathrm{ha}^{-1}$ were effective (81-90\%). Fifty LE applied by plane at $3 \mathrm{~L} \mathrm{ha}^{-1}$ or by a tractor propelled atomizer $\left(15 \mathrm{~L} \mathrm{ha}^{-1}\right)$ was inefficient. Fifty LE applied with a bar sprayer (134 and $\left.150 \mathrm{~L} \mathrm{ha}^{-1}\right)$ provided $87-90 \%$ control. When applied by plane $\left(15,20\right.$ and $\left.25 \mathrm{~L} \mathrm{ha}^{-1}\right)$ the control was $93-98 \%$. Air applications of $50 \mathrm{LE}$ using soybean oil $\left(5 \mathrm{~L} \mathrm{ha}^{-1}\right)$ and sugar cane molasses $\left(10 \mathrm{~L} \mathrm{ha}^{-1}\right)$ were efficient, providing $86-88 \%$ and $99 \%$ control, respectively. The results obtained from the pilot fields were similar to the ones obtained with the experiments.
\end{abstract}

Index terms: soybean crop, Lepidoptera, Noctuidae, Anticarsia gemmatalis, soybean oil, sugar cane molasses, Micronair nozzles, tractor propelled atomizer.

${ }^{1}$ Aceito para publicação em 14 de maio de 1999.

${ }^{2}$ Eng. Agrôn., Dr., Embrapa-Centro de Pesquisa Agropecuária do Oeste (CPAO), Caixa Postal 661, CEP 79804-970 Dourados, MS. E-mail: sergio@cpao.embrapa.br

${ }^{3}$ Eng. Agrôn., M.Sc., Embrapa-Centro Nacional de Pesquisa de Soja (CNPSo), Caixa Postal 231, CEP 86001-970 Londrina, PR. E-mail: gazzoni@cnpso.embrapa.br

\section{INTRODUÇÃO}

Pesquisas sobre a aplicação aérea de vírus de poliedrose nuclear (VPN) têm sido realizadas visando, principalmente, ao controle de insetos-pragas de espécies vegetais perenes. Nesses estudos, as aplicações foram geralmente efetuadas com aerona- 
ves equipadas com pulverizador de barra associado a bicos de pulverização do tipo leque (Stelzer et al., 1975, 1977; Kaupp \& Cunningham, 1977; Cunningham et al., 1979; Shepherd et al., 1984) ou com equipamentos constituídos de bicos centrífugos de tela rotativa (Groot et al., 1979) e bicos de discos rotativos (Yendol et al., 1977; Wollam et al., 1978).

Em apenas um dos trabalhos consultados, os autores usaram exclusivamente água (Thompson $\&$ Steinhaus, 1950); nos demais foram usadas combinações dos seguintes materiais: água (A); corante marcador (CM); espalhante adesivo (EA); melaço (ME), constituindo, geralmente, $25 \%$ do formulado; marcador fluorescente (MF), para avaliação das características das gotículas depositadas e protetor anti-raios ultravioleta (PARU). Assim, Thompson \& Steinhaus (1950) verificaram que a aplicação de 46,8 $\mathrm{L} \mathrm{ha}^{-1}$ de suspensão aquosa constituída de $2,35 \times 10^{11}$ corpos poliédricos de inclusão (CPI) de VPN, reduziram drasticamente a população de seu hospedeiro natural, Coslias philodice euritheme, em alfafa (Medicago sativa).

Stelzer et al. $(1975,1977)$ aplicaram $18,7 \mathrm{~L} \mathrm{ha}^{-1} \mathrm{de}$ formulados constituídos de A, ME, PARU, um adjuvante comercial destinado a formulações microbianas, $2,47 \times 10^{11}$ e 2,47x10 $10^{12}$ CPI de VPN de Orgyia pseudotsugata, praga de Pseudotsuga menziesii var. glauca e P. menziesii, obtendo reduções populacionais do inseto superiores a $90 \%$.

Yendol et al. (1977) aplicaram 18,7 $\mathrm{L} \mathrm{ha}^{-1}$ de calda composta de A, EA, ME, PARU e 2,5×10 ${ }^{13}$ de um isolado de VPN do inseto alvo, Lymantria dispar, praga de Quercus alba e Quercus spp. Decorridos 23 dias da aplicação, constataram redução populacional de cerca de $58 \%$ nas parcelas tratadas e desfolhamentos variando de $54 \%$ a $75 \%$, enquanto nas testemunhas a perda aproximou-se de $100 \%$. Wollam et al. (1978) verificaram que a população do mesmo inseto foi reduzida entre $59 \%$ e $79 \%$ com aplicação de $18,7 \mathrm{~L} \mathrm{ha}^{-1}$ de inseticida constituído de 2,5x10 ${ }^{12} \mathrm{CPI} \mathrm{ha}^{-1}$ do seu VPN, A, EA, ME e PARU.

Stelzer et al. (1977), aplicando 9,4 $\mathrm{L} \mathrm{ha}^{-1}$ de produto constituído de $2,5 \times 10^{11}$ CPI de VPN de O. pseudotsugata, A e PARU, registraram controle superior a 90\%, com excelente proteção às folhas de P. menziesii. Resultado semelhante foi obtido por Kaupp \& Cunningham (1977) e Groot et al. (1979) em experimento visando ao controle de Neodiprion lecontei sobre Pinus resinosa.

Cunningham et al. (1979) aplicaram, sobre Choristoneura fumiferana, 9,4 $\mathrm{L} \mathrm{ha}^{-1}$ de formulado (A, EA, ME, PARU e 7,5×10 ${ }^{10} \mathrm{CPI}$ de seu VPN), obtendo os seguintes porcentuais de controle: $33 \%$ a $92 \%$ em árvores de Abies balsamea e $37 \%$ a $76 \%$ em Picea glauca. Shepherd et al. (1984) registraram $77 \%$ a $100 \%$ de infeção em O. pseudotsugata, sobre árvores de Pseudotsuga menziesii, aplicando $11,3 \mathrm{~L} \mathrm{ha}^{-1}$ de um formulado (A, EA, ME, MF e 2,2 X10 ${ }^{11} \mathrm{CPI}$ de VPN da praga). Entretanto, Cunningham et al. (1979) constataram controle inconsistente de $C$. fumiferana após aplicação de $9,4 \mathrm{~L} \mathrm{ha}^{-1}$ de um formulado oleoso emulsionável de $7,5 \times 10^{9}$ CPI de seu VPN, mas enfatizaram que tal insucesso deveu-se à idade avançada das lagartas na data da aplicação.

As promissoras possibilidades de uso do vírus de poliedrose nuclear de Anticarsia gemmatalis (VPN Ag), como inseticida microbiano, para o controle da lagarta-da-soja (Carner \& Turnipseed, 1977; Moscardi, 1977), foram definitivamente consolidadas por Moscardi (1983), que demonstrou a eficiência do VPN Ag, aplicado, na forma de suspensão aquosa, com pulverizador de barra tracionado a trator. Contudo, não havia informações sobre práticas envolvendo aplicações através de aviação agrícola, para atender a demandas em áreas de grandes extensões, e com atomizador (canhão) tracionado por trator agrícola, razão pela qual objetivou-se, com este trabalho, a viabilização de técnicas que possibilitassem a utilização desses equipamentos.

\section{MATERIAL E MÉTODOS}

No período compreendido pelas safras de 1983/84 e 1987/88 foram conduzidos na região de Dourados, MS, seis experimentos com utilização de aeronave agrícola Ipanema equipada com Micronair (AU 3000 em quatro experimentos; AU 5000, nos restantes). Na amostragem de lagartas de A. gemmatalis, foi usado o método do pano (Boyer \& Dumas, 1963), que abrange $2 \mathrm{~m}$ de fileira de plantas, fazendo-se 10 amostragens por parcela e anotando-se, separadamente, o número de lagartas pequenas $(\leq 1,5 \mathrm{~cm})$ e grandes $(\geq 1,5 \mathrm{~cm})$.

Para a preparação das doses de VPN Ag, uma lagarta equivalente (LE) correspondeu a uma lagarta totalmente desenvolvida, morta pelo patógeno, que, de acordo com 
Moscardi (1983), contém cerca de $1,3 \times 10^{9}$ corpos poliédricos de inclusão (CPI). Os porcentuais de desfolhamento referem-se à área foliar consumida pelas lagartas e os seus valores foram obtidos a partir de leituras em três folíolos por planta. Os folíolos foram coletados ao acaso, nas partes superior, média e basal da soja, num total de 30 por parcela. O delineamento estatístico constou de blocos ao acaso, com três repetições. O tamanho das parcelas foi de $25 \times 150 \mathrm{~m}$ no primeiro experimento; 20 x 300 m no segundo e 600 × 300 m nos demais, enquanto as bordaduras laterais de cada parcela mediram entre $15-20 \mathrm{~m}$.

Foram testadas duas doses de VPN Ag (50 e $\left.100 \mathrm{LE} \mathrm{ha}^{-1}\right)$ em associação com óleo de soja, melaço de cana-de-açúcar e água, que foram aplicadas em diferentes volumes por hectare. As aplicações foram realizadas através de avião agrícola. Todavia, em um dos testes, foram usados dois equipamentos, tracionados por trator agrícola: atomizador (canhão) e pulverizador de barra, que foi utilizado em mais um experimento (Tabela 1). Nas contagens pós-aplicações, iniciadas no sétimo ou oitavo dia, as lagartas doentes, que apresentaram sintomas inequívocos de infecção e sem aparentes possibilidades de continuarem alimentando-se normalmente, foram consideradas como controladas. Para efeito de avaliação, anotaram-se apenas as lagartas sem sintoma de infecção pelo patógeno. Os números originais de lagartas grandes sadias e os porcentuais de desfolhamento foram transformados em $\sqrt{\mathrm{X}+0,5}$ e $\sqrt{\mathrm{P} / 100}$, respectivamente, antes de serem submetidos à ANOVA. Os contrastes entre as médias foram verificados pelo teste de Duncan a $5 \%$ de probabilidade, e os porcentuais de controle, determinados pela fórmula de Abbott (1925). Detalhamentos relativos à época de realização dos experimentos, às condições em que foram executados, aos tratamentos, às cultivares, às populações iniciais da praga e aos locais encontram-se nas Tabelas 1 e 2.

Com vistas à validação dos resultados obtidos experimentalmente, foram conduzidos três campos-piloto na Fazenda Dependência, Ponta Porã, MS, na safra 1986/87. No primeiro, de 38 ha, a cv. IAC-8 encontrava-se no final da fase vegetativa e a população anterior à aplicação dos tratamentos constituiu-se de 25 lagartas pequenas e cinco grandes. Foi aplicada a dose de $100 \mathrm{LE} \mathrm{ha}^{-1}$ do patógeno associado a óleo de soja $\left(5 \mathrm{~L} \mathrm{ha}^{-1}\right)$. No segundo campo,

TABELA 1. Caracterização de seis experimentos envolvendo aplicações aérea e terrestre de vírus de poliedrose nuclear de Anticarsia gemmatalis (VPN Ag), realizadas de 1983 a 1986, para controle da lagarta-da-soja na região da Grande Dourados.

\begin{tabular}{|c|c|c|c|c|c|c|c|c|c|c|c|c|}
\hline \multirow{2}{*}{$\begin{array}{l}\text { Experi- } \\
\text { mento }^{1}\end{array}$} & \multirow{2}{*}{$\begin{array}{c}\text { Ano } \\
\text { agrícola }\end{array}$} & \multicolumn{5}{|c|}{ Condições de trabalho da aeronave } & \multicolumn{3}{|c|}{ Condições atmosféricas } & \multicolumn{3}{|c|}{ Produto aplicado } \\
\hline & & 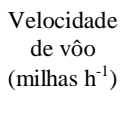 & $\begin{array}{c}\text { Altura } \\
\text { de vôo } \\
\text { (m) }\end{array}$ & $\begin{array}{c}\text { Abertura } \\
\text { de pás do } \\
\text { Micronair } \\
\text { (graus) }\end{array}$ & $\begin{array}{l}\text { Unidade } \\
\text { variável de } \\
\text { restrição } \\
\text { (VRU) }\end{array}$ & $\begin{array}{l}\text { Pressão } \\
\left(\mathrm{lb} \mathrm{pol}^{-2}\right)\end{array}$ & $\begin{array}{c}\text { Tempe- } \\
\text { ratura } \\
\left({ }^{\circ} \mathrm{C}\right)\end{array}$ & $\begin{array}{c}\text { Umidade } \\
\text { relativa } \\
(\%)\end{array}$ & $\begin{array}{c}\text { Velocidade } \\
\text { do vento } \\
\left(\mathrm{km} \mathrm{h}^{-1}\right)\end{array}$ & Veículo & $\begin{array}{l}\text { Volume } \\
\left(\mathrm{L} \mathrm{ha}^{-1}\right)\end{array}$ & $\begin{array}{c}\text { Dose } \\
\left(\mathrm{LE} \mathrm{ha}^{-1}\right)\end{array}$ \\
\hline $1^{2}$ & $1983 / 84$ & 105 & 3 & 30 & 5 & 30 & 29 & $79-75$ & $3-5$ & $\mathrm{H}_{2} \mathrm{O}$ & 3,0 & 50 e 100 \\
\hline $2^{3}$ & $1985 / 86$ & 105 & 5 & 35 & 11 & 20 & $21-23$ & $76-81$ & 10 & Óleo ${ }^{4}$ & 5,5 & 100 \\
\hline 2 & $1985 / 86$ & 105 & 5 & 35 & 11 & 20 & $21-23$ & $76-81$ & 10 & $\mathrm{Mel}^{5}$ & 10 & 100 \\
\hline 3 & $1986 / 87$ & 105 & 5 & 35 & 11 & 20 & 30 & 75 & 10 & Óleo & 5 & $50^{6}$ e 100 \\
\hline 4 & $1986 / 87$ & 105 & 5 & 35 & 11 & 20 & 30 & 76 & 10 & Óleo & 5 & $50^{6}$ e 100 \\
\hline 4 & $1986 / 87$ & 105 & 5 & 35 & 13 & 30 & 31 & 75 & 10 & Mel. & 10 & $50^{6}$ e 100 \\
\hline 5 & $1987 / 88$ & 110 & 5 & 50 & 11 & 28 & $24-29$ & $70-87$ & $5-10$ & $\mathrm{H}_{2} \mathrm{O}$ & 15 & 100 \\
\hline 5 & $1987 / 88$ & 110 & 5 & 50 & 13 & 22,5 & 24-29 & $70-87$ & $5-10$ & $\mathrm{H}_{2} \mathrm{O}$ & 20 & 100 \\
\hline 5 & $1987 / 88$ & 110 & 5 & 50 & 13 & 30 & $24-29$ & $70-87$ & $5-10$ & $\mathrm{H}_{2} \mathrm{O}$ & 25 & 100 \\
\hline 6 & $1987 / 88$ & 110 & 5 & 50 & 11 & 30 & $28-30$ & $65-70$ & $8-10$ & $\mathrm{H}_{2} \mathrm{O}$ & 10 & 50 \\
\hline 6 & $1987 / 88$ & 110 & 5 & 50 & 11 & 30 & $28-30$ & $65-70$ & $8-10$ & $\mathrm{H}_{2} \mathrm{O}$ & 15 & 50 \\
\hline 6 & $1987 / 88$ & 110 & 5 & 50 & 13 & 30 & $28-30$ & $65-70$ & $8-10$ & $\mathrm{H}_{2} \mathrm{O}$ & 20 & 50 \\
\hline 6 & $1987 / 88$ & 110 & 5 & 50 & 13 & 30 & $28-30$ & $65-70$ & $8-10$ & $\mathrm{H}_{2} \mathrm{O}$ & 25 & 50 \\
\hline
\end{tabular}

${ }^{1}$ Em todos os experimentos houve um tratamento sem aplicação (testemunha); número de ordem repetido indica tratamento diferente no mesmo experimento.

${ }^{2}$ Houve mais dois tratamentos com o patógeno; em ambos aplicou-se, via terrestre, suspensões aquosas de 50 LE ha-1 de VPN Ag com equipamentos tracionados por trator; em um deles aspergiu-se $154 \mathrm{~L} \mathrm{ha}^{-1}$ com pulverizador de barra e no outro $15 \mathrm{~L} \mathrm{ha}^{-1}$, com atomizador (canhão).

${ }^{3}$ No experimento 2 houve mais um tratamento em que foram aplicados $50 \mathrm{LE} \mathrm{ha}^{-1}$ de VPN Ag na forma de $130 \mathrm{~L} \mathrm{ha}^{-1}$ de suspensão aquosa com pulverizador de barra.

4 Óleo de soja.

5 Melaço de cana-de-açúcar.

${ }^{6}$ Doses escritas na mesma linha indicam que constituem-se nas únicas distinções entre dois tratamentos de um mesmo experimento. Por conseguinte, todas as demais condições foram iguais. 
de 100 ha da cv. IAS-5 em início de floração, pulverizou-se o mesmo tratamento sobre uma população média de 30 lagartas pequenas e dez grandes. No terceiro, constituído de seis cultivares, o VPN Ag foi aplicado nas doses de 50 e $75 \mathrm{LE} \mathrm{ha}^{-1}$, via aérea, na forma de suspensões aquosas de 15 e $25 \mathrm{~L} \mathrm{ha}^{-1}$.

\section{RESULTADOS E DISCUSSÃO}

Dois experimentos mostraram que $50 \mathrm{LE}$ de VPN Ag, aplicadas com pulverizador de barra tracionado por trator agrícola, na forma de suspensões aquosas de 154 e $130 \mathrm{~L} \mathrm{ha}^{-1}$, controlaram, res- pectivamente, $75 \%$ e $80 \%$ das lagartas de A. gemmatalis no oitavo dia após aplicação dos tratamentos (DAT). No décimo DAT, o controle foi de $90 \%$ e $87 \%$, respectivamente (Tabelas 3 e 4). Tais resultados aproximam-se dos relatados por Carner \& Turnipseed (1977) e Moscardi (1983). Constatou-se que o volume de líquido a ser utilizado como meio para a aplicação do inseticida biológico pode ser crítico, pois aplicações de 50 ou 100 LE, quando efetuadas com volume de calda variando entre $3 \mathrm{~L} \mathrm{ha}^{-1}$ para avião ou $15 \mathrm{~L} \mathrm{ha}^{-1}$ para canhão - testados, inicialmente, com o objetivo de reduzir custos pela diminuição de reabastecimento - mostraram-se

TABELA 2. Complemento da caracterização dos experimentos envolvendo aplicações de VPN Ag para controlar a lagarta-da-soja, na região da Grande Dourados, de 1983 a1988.

\begin{tabular}{|c|c|c|c|c|c|c|c|}
\hline \multirow[t]{2}{*}{ Experimento } & \multirow{2}{*}{$\begin{array}{c}\text { Ano } \\
\text { agrícola }\end{array}$} & \multicolumn{2}{|c|}{ Planta de soja } & \multicolumn{2}{|c|}{ População inicial de larvas } & \multicolumn{2}{|c|}{ Propriedade } \\
\hline & & Cultivar & $\begin{array}{l}\text { Estádio no } \\
\text { momento da } \\
\text { aplicação }\end{array}$ & $\begin{array}{c}\text { Lagartas } \\
\text { grandes } \\
(>1,5 \mathrm{~cm})\end{array}$ & $\begin{array}{l}\text { Lagartas } \\
\text { pequenas } \\
(<1,5 \mathrm{~cm})\end{array}$ & Denominação & Município \\
\hline 1 & $1983 / 84$ & UFV-5 & Vegetativo & - & 70 & Fazenda Itamarati & Ponta Porã, MS \\
\hline 2 & $1985 / 86$ & Dourados & Floracão & 15,9 & 67,2 & Embrapa-CPAO & Dourados, MS \\
\hline 3 & $1986 / 87$ & Doko & Floração & 19,0 & 49 & Fazenda Triunfo & Ponta Porã, MS \\
\hline 4 & $1986 / 87$ & UFV-5 & Vegetativo & - & 30 & Fazenda Campanário & Laguna Carapã, MS \\
\hline 5 & $1987 / 88$ & UFV-5 & Vegetativo & - & 35 & Fazenda Campanário & Laguna Carapã, MS \\
\hline 6 & $1987 / 88$ & IAC- 8 & Vegetativo & - & 100 & Fazenda Campanário & Laguna Carapã, MS \\
\hline
\end{tabular}

TABELA 3. Lagartas sadias pequenas (LPS) e grandes (LGS) de Anticarsia gemmatalis, porcentagens de desfolhamento (\%D) e eficiência (\%E) após aplicações de VPN Ag, em Ponta Porã, MS, na safra 1983/84. Experimento $1^{1}$.

\begin{tabular}{|c|c|c|c|c|c|c|c|c|c|}
\hline \multirow[t]{3}{*}{ Tratamento } & \multicolumn{3}{|c|}{ Pré-contagem } & \multicolumn{6}{|c|}{ Dias após a aplicação dos tratamentos } \\
\hline & \multirow[t]{2}{*}{ LPS } & \multirow[t]{2}{*}{ LGS } & \multirow[t]{2}{*}{$\% \mathrm{D}$} & \multicolumn{3}{|c|}{8} & \multicolumn{3}{|c|}{10} \\
\hline & & & & LGS & $\% \mathrm{E}$ & $\% \mathrm{D}$ & LGS & $\% \mathrm{E}$ & $\% \mathrm{D}$ \\
\hline Barra $^{2} 50 \mathrm{LE} 154 \mathrm{~L} \mathrm{ha}^{-1}$ & 64,70 & 3,30 & 5,70 & $12,50 \mathrm{a}$ & 75 & $18,93 a$ & $4,40 \mathrm{a}$ & 90 & $21,10 \mathrm{a}$ \\
\hline Canhão $^{3} 50 \mathrm{LE} 15 \mathrm{~L} \mathrm{ha}^{-1}$ & 71,50 & 3,10 & 7,00 & $27,73 b$ & 44 & $25,00 \mathrm{~b}$ & $25,00 \mathrm{~b}$ & 42 & $37,35 b$ \\
\hline Avião ${ }^{4} 50 \mathrm{LE} 3 \mathrm{~L} \mathrm{ha}^{-1}$ & 71,43 & 3,10 & 7,40 & $36,63 \mathrm{bc}$ & 26 & $31,10 \mathrm{~b}$ & $23,60 \mathrm{~b}$ & 45 & $40,72 b$ \\
\hline Avião $100 \mathrm{LE} 3 \mathrm{~L} \mathrm{ha}^{-1}$ & 67,00 & 2,70 & 7,90 & $30,90 \mathrm{bc}$ & 38 & $25,70 \mathrm{ab}$ & $26,50 \mathrm{~b}$ & 38 & $40,90 \mathrm{~b}$ \\
\hline Testemunha & 77,70 & 2,70 & 6,90 & $49,70 \mathrm{c}$ & - & $31,00 \mathrm{~b}$ & $43,13 \mathrm{c}$ & - & $58,80 \mathrm{c}$ \\
\hline C.V. $(\%)$ & & & & 10,19 & & 12,50 & 14,90 & & 14,00 \\
\hline $\mathrm{F}(5 \%)$ & & & & $12,00 *$ & & $7,11 *$ & $13,00 *$ & & $6,35 *$ \\
\hline
\end{tabular}

1 Médias seguidas da mesma letra não diferem estatisticamente entre si (Duncan, 5\%).

2 Pulverizador de barra tracionado por trator agrícola, $50 \mathrm{LE}$ aplicadas na forma de suspensão aquosa de $154 \mathrm{~L} \mathrm{ha}^{-1}$.

3 Atomizador tracionado por trator agrícola, $50 \mathrm{LE}$ aplicadas na forma de suspensão aquosa de $15 \mathrm{~L} \mathrm{ha}^{-1}$.

4 Avião agrícola, $50 \mathrm{LE}$ aplicadas como suspensão aquosa de $3 \mathrm{~L} \mathrm{ha}^{-1}$.

5 Avião agrícola, $100 \mathrm{LE}$ aplicadas como suspensão aquosa de $3 \mathrm{~L} \mathrm{ha}^{-1}$. 
ineficientes (Tabela 3). A possível explicação para tais resultados pode estar relacionada com a rápida evaporação que sofre uma gota expelida de um Micronair ou de um canhão, sob alta pressão. Em contato com o ar atmosférico, e na presença de altas temperaturas observadas na região durante a safra de soja, as gotas diminuem rapidamente de tamanho, podendo evaporar quase totalmente, sendo carregadas pelas correntes ascendentes, ou mesmo distribuídas sobre uma área maior do que a originalmente prevista. Diante do exposto, as doses pretendidas (50 e $100 \mathrm{LE}$ ) provavelmente não foram depositadas sobre as plantas de soja, principalmente nos terços médio e inferior, onde se concentra a maioria das lagartas de até quarto ínstar (Ferreira \& Panizzi,1978), que são as mais suscetíveis ao vírus (Moscardi, 1983), redundando em baixa mortalidade. Com base nessa hipótese, buscou-se melhorar a cobertura das plantas no experimento 2 (Tabela 4), aumentando-se o volume da aplicação aérea e alterando-se o veículo para óleo de soja $\left(5,5 \mathrm{~L} \mathrm{ha}^{-1}\right)$ ou melaço $\left(10 \mathrm{~L} \mathrm{ha}^{-1}\right)$, mas mantendo-se a dose de vírus em 100 LE. Todos os tratamentos com aplicação de VPN Ag foram semelhantes entre si tanto aos 7 DAT $(75 \%$ a $83 \%)$ quanto nas demais datas de amostragem $(71 \%$ a $87 \%$ de controle), e diferindo estatisticamente da testemunha. A melhoria na eficiência da atuação do inseticida biológico em relação ao estudo anterior evidencia-se quando é analisado o desfolhamento cau- sado pelas lagartas, visto que as parcelas que receberam o produto por via aérea sempre mostraram-se menos desfolhadas que a testemunha, o mesmo não ocorrendo na aplicação com barra, semelhante estatisticamente à testemunha e à aplicação com avião (Tabela 4)

O sucesso na aplicação de VPN Ag por via aérea, com a adição de melaço ou óleo de soja, suscitou a necessidade de avaliação da menor dose do inseticida que efetuasse um bom controle de A. gemmatalis, o que foi concretizado mediante o experimento 3 . A análise estatística mostrou não haver diferença entre as doses de 50 e $100 \mathrm{LE}$, quando aplicadas através de $5 \mathrm{~L} \mathrm{ha}^{-1}$ de óleo de soja, evidenciando um bom controle a partir de 8 DAT (82\% a 93\%), o mesmo sendo observado aos 10 e 12 DAT, com porcentuais de controle variando entre $76 \%$ e $89 \%$ (Tabela 5). Prosseguindo com o estudo, no experimento 4 comparou-se a aplicação aérea com melaço (10 $\left.\mathrm{L} \mathrm{ha}^{-1}\right)$ ao realizado com óleo de soja $\left(5 \mathrm{~L} \mathrm{ha}^{-1}\right)$, nas doses de 50 e 100 LE. Ambos tratamentos mostraram-se estatisticamente equivalentes (Tabela 6), propiciando bom controle da lagarta-dasoja (entre $88 \%$ e $99 \%$ ). Desta forma foi possível estabelecer a viabilidade de uso de 50 LE de melaço ou óleo de soja, quando aplicados por via aérea, em volumes de 10 e $5 \mathrm{~L} \mathrm{ha}^{-1}$, respectivamente.

Como as aplicações aéreas de inseticidas são utilizadas tendo como veículo a água, tornava-se

TABELA 4. Lagartas grandes sadias (LGS), de Anticarsia gemmatalis, porcentagens de eficiência (\%E) e desfolhamento (\%D) após aplicações de VPN Ag, em Dourados, MS, na safra 1985/86. Experimento 21.

\begin{tabular}{|c|c|c|c|c|c|c|c|c|c|c|c|c|}
\hline \multirow[t]{3}{*}{ Tratamento } & \multicolumn{12}{|c|}{ Dias após a aplicação dos tratamentos } \\
\hline & \multicolumn{3}{|c|}{7} & \multicolumn{3}{|c|}{8} & \multicolumn{3}{|c|}{9} & \multicolumn{3}{|c|}{10} \\
\hline & LGS & $\% \mathrm{E}$ & $\% \mathrm{D}$ & LGS & $\% \mathrm{E}$ & $\% \mathrm{D}$ & LGS & $\% \mathrm{E}$ & $\% \mathrm{D}$ & LGS & $\% \mathrm{E}$ & $\% \mathrm{D}$ \\
\hline VA100LEOL5, $5^{2}$ & $6,67 \mathrm{a}$ & 75 & $24,88 \mathrm{a}$ & $6,55 \mathrm{a}$ & 71 & $26,15 \mathrm{a}$ & $3,30 \mathrm{a}$ & 81 & $26,79 \mathrm{a}$ & $3,50 \mathrm{a}$ & 82 & $26,78 \mathrm{a}$ \\
\hline VA100LEM10 ${ }^{3}$ & $4,62 \mathrm{a}$ & 83 & $24,69 \mathrm{a}$ & $4,86 a$ & 79 & $25,51 \mathrm{a}$ & $3,93 \mathrm{a}$ & 78 & $24,92 \mathrm{a}$ & $3,87 \mathrm{a}$ & 81 & $24,28 \mathrm{a}$ \\
\hline PB50LE130 4 & $5,71 \mathrm{a}$ & 79 & $31,13 \mathrm{ab}$ & $4,59 \mathrm{a}$ & 80 & $33,31 \mathrm{ab}$ & $3,05 \mathrm{a}$ & 83 & $33,85 \mathrm{ab}$ & $2,62 \mathrm{a}$ & 87 & $35,04 \mathrm{ab}$ \\
\hline Testemunha & $26,69 b$ & - & $38,50 \mathrm{~b}$ & $22,94 \mathrm{~b}$ & - & $42,93 \mathrm{~b}$ & $17,52 \mathrm{~b}$ & - & $43,36 \mathrm{~b}$ & $19,88 \mathrm{~b}$ & - & $42,19 b$ \\
\hline C.V. $(\%)$ & 16,83 & & 11,12 & 17,89 & & 10,57 & 19,46 & & 12,02 & 23,22 & & 13,87 \\
\hline $\mathrm{F}(5 \%)$ & $20,12^{*}$ & & $3,66^{*}$ & $15,53^{*}$ & & $5,56^{*}$ & $15,78^{*}$ & & $4,52 *$ & $13,80 *$ & & $3,60^{*}$ \\
\hline
\end{tabular}

1 Médias seguidas da mesma letra não diferem estatisticamente entre si (Duncan, 5\%).

2 Via aérea, $100 \mathrm{LE}$ aplicadas com óleo de soja $\left(5,5 \mathrm{~L} \mathrm{ha}^{-1}\right)$.

3 Via aérea, $100 \mathrm{LE}$ aplicadas com melaço de cana-de-açúcar $\left(10 \mathrm{~L} \mathrm{ha}^{-1}\right)$.

${ }^{4}$ Pulverizador de barra tracionado por trator agrícola, $50 \mathrm{LE}$ aplicadas na forma de $130 \mathrm{~L} \mathrm{ha}^{-1}$ de suspensão aquosa. 
necessário verificar a eficiência do vírus da lagarta-da-soja com volumes de água superiores aos estudados no experimento 1 , observando-se, porém, os parâmetros técnicos estabelecidos para as aeronaves agrícolas. Assim, no experimento 5, utilizaram-se 15, 20 e $25 \mathrm{~L} \mathrm{ha}^{-1}$ de água para aplicar $100 \mathrm{LE}$ de VPN Ag. Os resultados expostos na Tabela 7 evidenciaram que os tratamentos foram estatisticamente equivalentes, proporcionando controle eficiente da lagarta-da-soja, em especial aos 9 DAT, quando o controle variou entre $85 \%$ e $90 \%$. Os mesmos volumes de suspensão aquosa, ao lado de outro de $10 \mathrm{~L} \mathrm{ha}^{-1}$, mas veiculando $50 \mathrm{LE}$, foram aplicados no experimento 6 . As aplicações de 15, 20 e $25 \mathrm{~L} \mathrm{ha}^{-1}$ mantiveram o nível de eficiência, que variou de $93 \%$ a $98 \%$ nas avaliações realizadas

TABELA 5. Lagartas grandes sadias (LGS), de Anticarsia gemmatalis, porcentagens de eficiência (\%E) e desfolhamento (\%D), após aplicações de VPN Ag em Ponta Porã, MS, na safra 1986/87. Experimento $3^{1}$.

\begin{tabular}{|c|c|c|c|c|c|c|c|c|c|}
\hline \multirow[t]{3}{*}{ Tratamento } & \multicolumn{9}{|c|}{ Dias após a aplicação dos tratamentos } \\
\hline & \multicolumn{3}{|c|}{8} & \multicolumn{3}{|c|}{10} & \multicolumn{3}{|c|}{12} \\
\hline & LGS & $\% \mathrm{E}$ & $\% \mathrm{D}$ & LGS & $\% \mathrm{E}$ & $\% \mathrm{D}$ & LGS & $\% \mathrm{E}$ & $\% \mathrm{D}$ \\
\hline${\text { VA100LEOL } 5^{2}}^{2}$ & $1,43 a$ & 93 & $29 a$ & $2,33 \mathrm{a}$ & 89 & $29 \mathrm{a}$ & $2,66 a$ & 85 & $27 \mathrm{a}$ \\
\hline VA50LEOL5 $^{3}$ & $3,80 \mathrm{~b}$ & 82 & $35 \mathrm{ab}$ & $2,93 \mathrm{a}$ & 86 & $34 \mathrm{a}$ & $4,47 \mathrm{a}$ & 76 & $28 \mathrm{a}$ \\
\hline Testemunha & $20,73 \mathrm{c}$ & - & $49 b$ & $21,50 \mathrm{~b}$ & - & $50 \mathrm{~b}$ & $18,33 \mathrm{~b}$ & - & $48 b$ \\
\hline C.V. $(\%)$ & 10,37 & & 11,37 & 29,00 & & 11,95 & 15,37 & & 12,48 \\
\hline $\mathrm{F}(5 \%)$ & $11,3 *$ & & $8,45^{*}$ & $13,42^{*}$ & & $7,25^{*}$ & $31,03 *$ & & $5,25^{*}$ \\
\hline
\end{tabular}

${ }^{1}$ Médias seguidas da mesma letra não diferem estatisticamente entre si (Duncan, 5\%).

$2100 \mathrm{LE}$ aplicadas com $5 \mathrm{~L} \mathrm{ha}^{-1}$ de óleo de soja.

$350 \mathrm{LE}$ aplicadas com $5 \mathrm{~L} \mathrm{ha}^{-1}$ de óleo de soja.

TABELA 6. Lagartas grandes sadias (LGS), de Anticarsia gemmatalis, porcentagens de eficiência $(\% \mathrm{E})$ e desfolhamento $(\% \mathrm{D})$ após aplicações de VPN Ag, em Laguna Carapã, MS, na safra 1986/87. Experimento $4^{1}$.

\begin{tabular}{lccc}
\hline Tratamento & LGS & $\% \mathrm{E}$ & $\% \mathrm{D}$ \\
\hline OL 5 L- 100 LE & $0,40 \mathrm{a}$ & 98 & 14,80 \\
OL 5 L- 50 LE & $1,90 \mathrm{~b}$ & 88 & 15,30 \\
M10 L - 100 LE & $0,67 \mathrm{ab}$ & 96 & 16,00 \\
M10 L- 50 LE & $0,20 \mathrm{a}$ & 99 & 18,30 \\
Testemunha & $16,50 \mathrm{c}$ & - & 18,50 \\
\hline C.V. $(\%)$ & 14,80 & & 10,20 \\
F $(5 \%)$ & $8,90^{*}$ & & $2,05^{\text {ns }}$ \\
\hline
\end{tabular}

${ }^{1}$ Médias seguidas de mesma letra não diferem estatisticamente entre si (Duncan, 5\%).

$2100 \mathrm{LE}$ aplicadas, via aérea, com $5 \mathrm{~L} \mathrm{ha}^{-1}$ de óleo de soja.

$350 \mathrm{LE}$ aplicadas, via aérea, com $5 \mathrm{~L} \mathrm{ha}^{-1}$ de óleo de soja.

$4100 \mathrm{LE}$ aplicadas, via aérea, com $10 \mathrm{~L} \mathrm{ha}^{-1}$ de melaço de cana-de-açúcar.

$550 \mathrm{LE}$ aplicadas, via aérea, com $10 \mathrm{~L} \mathrm{ha}^{-1}$ de melaço de cana-de-açúcar.
TABELA 7. Lagartas grandes sadias (LGS), de Anticarsia gemmatalis, porcentagens de eficiência $(\% \mathrm{E})$ e desfolhamento $(\% \mathrm{D})$ após aplicações de VPN Ag, em Laguna Carapã, MS, na safra 1987/88. Experimento $5^{1}$.

\begin{tabular}{|c|c|c|c|c|c|c|}
\hline \multirow{3}{*}{$\begin{array}{l}\text { Tratamento } \\
\left(\mathrm{L} \mathrm{ha}^{-1}\right)\end{array}$} & \multicolumn{6}{|c|}{ Dias após a aplicação do patógeno } \\
\hline & \multicolumn{3}{|c|}{7} & \multicolumn{3}{|c|}{9} \\
\hline & LGS & $\% \mathrm{E}$ & $\% \mathrm{D}$ & LGS & $\% \mathrm{E}$ & $\% \mathrm{D}$ \\
\hline $15^{2}$ & $2,89 \mathrm{a}$ & 77 & $23,73 a$ & $1,75 \mathrm{a}$ & 85 & $26,33 a$ \\
\hline $20^{2}$ & $1,27 \mathrm{a}$ & 90 & $26,23 a$ & $2,22 \mathrm{a}$ & 81 & $26,10 \mathrm{a}$ \\
\hline $25^{2}$ & $2,05 \mathrm{a}$ & 84 & $18,50 \mathrm{a}$ & $1,22 \mathrm{a}$ & 90 & $23,30 \mathrm{a}$ \\
\hline Testemunha & $12,81 \mathrm{~b}$ & - & $31,60 \mathrm{a}$ & $11,92 b$ & - & $33,33 \mathrm{a}$ \\
\hline C.V. $(\%)$ & 23,98 & & 7,00 & 22,64 & & 6,55 \\
\hline $\mathrm{F}(5 \%)$ & $13,00^{*}$ & & $1,95 \mathrm{~ns}$ & $15,52^{*}$ & & $2,01^{\mathrm{ns}}$ \\
\hline
\end{tabular}

${ }^{1}$ Médias seguidas de mesma letra não diferem estatisticamente entre si (Duncan, 5\%).

2 Suspensões aquosas de 100 LE. 
aos 6 e 8 DAT (Tabela 8). Conforme a mesma tabela, o volume de $10 \mathrm{~L} \mathrm{ha}^{-1}$ proporcionou controle de $92 \%$ e $96 \%$ aos 6 e 8 DAT, respectivamente, mas carece de confirmação em experimento ou de validação em termos de lavoura. Esses resultados permitiram aferir o volume mínimo de água a ser utilizado na aplicação aérea de VPN Ag, o qual, de acordo com o estudo realizado, situa-se na faixa de $15 \mathrm{~L} \mathrm{ha}^{-1}$.

Após a obtenção desses resultados, foram realizadas aplicações em lavouras com a finalidade de validá-los. No município de Ponta Porã, a aplicação aérea de 100 LE de VPN Ag foi efetuada com o auxílio de $5 \mathrm{~L} \mathrm{ha}^{-1}$ de óleo de soja, em duas lavouras. As amostragens realizadas indicaram que houve um controle de $90 \%$ das lagartas presentes em uma área, e de $80 \%$ em outra, aos 10 DAT (Tabela 9).

No mesmo município, na propriedade denominada Fazenda Dependência, 854 ha de soja, infestados com a lagarta-da-soja, foram submetidos a aplicações aéreas utilizando-se 50 ou 75 LE, veiculados através de $15 \mathrm{~L} \mathrm{ha}^{-1}$ de água, além de uma aplicação de $75 \mathrm{LE}$ através de $25 \mathrm{~L} \mathrm{ha}^{-1}$. A avaliação das áreas aplicadas demonstrou que o tratamento com VPN Ag, com qualquer dose ou volume de calda utilizado, reduziu a população da lagarta-da-soja $(80 \%$ a $92 \%$ ) aos 10 DAT (Tabela 10).

TABELA 8. Lagartas sadias grandes (LGS), de Anticarsia gemmatalis, porcentagens de eficiência (\%E) e desfolhamento (\%D) após aplicações de VPN Ag, em Laguna Carapã, MS, na safra 1987/88. Embrapa-CPAO. Experimento 6 $^{1}$.

\begin{tabular}{|c|c|c|c|c|c|c|}
\hline \multirow{3}{*}{$\begin{array}{l}\text { Tratamento } \\
\left(\mathrm{L} \mathrm{ha}^{-1}\right)\end{array}$} & \multicolumn{6}{|c|}{ Dias após a aplicação do patógeno } \\
\hline & \multicolumn{3}{|c|}{6} & \multicolumn{3}{|c|}{8} \\
\hline & LGS & $\% \mathrm{E}$ & $\% \mathrm{D}$ & LGS & $\% \mathrm{E}$ & $\% \mathrm{D}$ \\
\hline $10^{2}$ & $2,07 \mathrm{a}$ & 92 & 11,30 & $2,06 a$ & 96 & 13,0 \\
\hline $15^{2}$ & $1,79 \mathrm{a}$ & 93 & 13,60 & $1,89 \mathrm{a}$ & 97 & 14,0 \\
\hline $20^{2}$ & $1,50 \mathrm{a}$ & 94 & 11,70 & $2,06 a$ & 96 & 12,0 \\
\hline $25^{2}$ & $1,25 \mathrm{a}$ & 95 & 11,50 & $1,05 \mathrm{a}$ & 98 & 11,0 \\
\hline Testemunha & $24,41 b$ & - & 12,83 & $53,88 \mathrm{~b}$ & - & 53,0 \\
\hline C.V. (\%) & 19,82 & & & $15,32 *$ & & 17,15 \\
\hline $\mathrm{F}(5 \%)$ & $40,47^{*}$ & & $1,05^{\mathrm{ns}}$ & $123,77^{*}$ & & 35,75 \\
\hline
\end{tabular}

${ }^{1}$ Médias seguidas de mesma letra não diferem estatisticamente entre si (Duncan, 5\%).

2 Suspensões aquosas de 50 LE.

TABELA 9. Resultados obtidos em dois campos-piloto tratados com VPN Ag, no ano agrícola 1986/87.

\begin{tabular}{|c|c|c|c|c|c|c|c|c|c|c|c|}
\hline \multirow[t]{3}{*}{ Local } & \multirow[t]{3}{*}{ Área } & \multirow[t]{3}{*}{$\mathrm{LE} \mathrm{ha}^{-1}$} & \multirow[t]{3}{*}{ Veículo } & \multirow{3}{*}{$\begin{array}{l}\text { Volume } \\
\left(\mathrm{L} \mathrm{ha}^{-1}\right)\end{array}$} & \multirow[t]{3}{*}{ Cultivar } & \multicolumn{4}{|c|}{ População } & \multirow{3}{*}{$\begin{array}{l}\mathrm{D}^{2} \\
(\%)\end{array}$} & \multirow{3}{*}{$\begin{array}{l}\mathrm{RP}^{3} \\
(\%)\end{array}$} \\
\hline & & & & & & \multicolumn{2}{|c|}{ Inicial } & \multicolumn{2}{|c|}{ Final $^{1}$} & & \\
\hline & & & & & & $\mathrm{LG}^{4}$ & $\mathrm{LP}^{5}$ & LG & LP & & \\
\hline Ponta Porã & 38 & 100 & Óleo de soja & 5 & IAC-8 & 5,00 & 25,00 & 3,00 & - & 18 & 90 \\
\hline Ponta Porã & 100 & 100 & Óleo de soja & 5 & IAS-5 & 10,00 & 30,00 & 3,00 & 5,00 & 25 & 80 \\
\hline
\end{tabular}


TABELA 10. Áreas de soja da Fazenda Dependência, Ponta Porã, MS, local de controle da lagarta-da-soja pela aplicação aérea de suspensões aquosas de VPN Ag, na safra 1986/87.

\begin{tabular}{|c|c|c|c|c|c|c|c|c|c|c|}
\hline \multirow{3}{*}{$\begin{array}{l}\text { Volume de } \\
\text { suspensão } \\
\left(\mathrm{L} \mathrm{ha}^{-1}\right)\end{array}$} & \multirow{3}{*}{$\begin{array}{l}\text { VPN Ag } \\
\left(\mathrm{LE} \mathrm{ha}^{-1}\right)\end{array}$} & \multirow[t]{3}{*}{ Cultivar } & \multirow{3}{*}{$\begin{array}{c}\text { Área } \\
\text { tratada } \\
\text { (ha) }\end{array}$} & \multicolumn{4}{|c|}{ População de A. gemmatalis } & \multirow{3}{*}{$\begin{array}{c}\mathrm{D}^{2} \\
(\%)\end{array}$} & \multirow{3}{*}{$\begin{array}{l}\mathrm{RP}^{3} \\
(\%)\end{array}$} & \multirow{3}{*}{$\begin{array}{c}\text { Rendimento } \\
\text { de grãos } \\
\left(\mathrm{kg} \mathrm{ha}^{-1}\right)\end{array}$} \\
\hline & & & & \multicolumn{2}{|c|}{ Inicial } & \multicolumn{2}{|c|}{ Final $^{1}$} & & & \\
\hline & & & & $\mathrm{LG}^{4}$ & $\mathrm{LP}^{5}$ & LG & LP & & & \\
\hline 25 & 75 & BR-4 & 185 & 14 & 35 & 3 & 4 & 20 & 86 & 3.336 \\
\hline 15 & 75 & IAS-5 & 122 & 10 & 30 & 2 & 3 & 17 & 83 & 3.163 \\
\hline 15 & 75 & Bossier & 30 & 8 & 32 & 4 & 4 & 18 & 80 & 3.136 \\
\hline 15 & 75 & IAC-12 & 135 & 13 & 29 & 1 & 5 & 13 & 86 & 3.089 \\
\hline 15 & 75 & Dourados & 36 & 8 & 36 & 3 & 3 & 18 & 86 & 2.877 \\
\hline 15 & 75 & Cobb & 226 & 12 & 36 & 2 & 2 & 20 & 92 & 3.104 \\
\hline 15 & 50 & BR-4 & 45 & 10 & 30 & 0,5 & 4 & 19 & 89 & 3.336 \\
\hline 15 & 50 & Cobb & 75 & 12 & 29 & 0,7 & 0,8 & 18 & 86 & 3.304 \\
\hline
\end{tabular}

1 Avaliações realizadas dez dias após as aplicações.

2 Desfolhamento.

3 Redução populacional.

${ }^{4}$ Lagartas grandes.

${ }^{5}$ Lagartas pequenas.

\section{CONCLUSÕES}

1. Cinqüenta LE de VPN Ag, aplicadas com avião agrícola equipado com Micronair, na forma de suspensões aquosas de 15,20 e $25 \mathrm{~L} \mathrm{ha}^{-1}$, e associadas a óleo de soja $\left(5 \mathrm{~L} \mathrm{ha}^{-1}\right)$ e a melaço de cana-de-açúcar $\left(10 \mathrm{~L} \mathrm{ha}^{-1}\right)$, controlam eficientemente a lagarta-da-soja.

2. Suspensões aquosas de 50 LE de VPN Ag aplicadas, via atomizador $\left(15 \mathrm{~L} \mathrm{ha}^{-1}\right)$ e de 50 e $100 \mathrm{LE}$, via avião agrícola equipado com Micronair $\left(3 \mathrm{~L} \mathrm{ha}^{-1}\right)$, não controlam eficientemente a lagarta-da-soja.

\section{REFERÊNCIAS}

ABBOTT, W. A method of computing the effectiveness of an insecticide. Journal of Economic Entomology, Lanham, v.18, p.265-267, 1925.

BOYER, W.P.; DUMAS, W. Soybean insects survey as used in Arkansas. Cooperative Economic Insect Report, Hyattsville, v.13, n.6, p.91-92, 1963.

CARNER, G.R.; TURNIPSEED, S.G. Potential of a nuclear polyhedrosis virus for control of the velvetbean caterpillar in soybean. Journal of Economic Entomology, Lanham, v.70, n.5, p.608-610, 1977.
CUNNINGHAM, J.C.; HOWSE, G.M.; McPHEE, J.R.; GROOT, P. de; WHITE, M.B.E. Aerial application of spruce budworm baculovirus: replicated tests with an aqueous formulation and a trial using an oil formulation in 1978. Sault Sainte Marie : Canadian Forestry Service, 1979. 19p. (Report, FPM-X-21).

FERREIRA, B.S.C.; PANIZZI, A.R. Distribuição de ovos e lagartas de Anticarsia gemmatalis Hübner em plantas de soja. Anais da Sociedade Entomologica do Brasil, Jaboticabal, v.7, n.1, p.54-59, 1978.

GROOT, P. de; CUNNINGHAM, J.C.; McPHEE, J.R. Control of red-headed pine sawfly with a baculovirus in Ontario in 1978 and a survey of areas treated in previous years. Sault Sainte Marie : Canadian Forestry Service, 1979. 14p. (Report, FPM-X-20).

KAUPP, W.J.; CUNNINGHAM, J.C. Aerial application of a nuclear polyhedrosis virus against the red-headed pine sawfly, Neodiprion lecontei (Fitch.). Sault Sainte Marie : Canadian Forestry Service, 1977. 26p. (Information Report, IP-4).

MOSCARDI, F. Control of Anticarsia gemmatalis Hübner on soybean with a baculovirus and selected insecticides and their effect on natural epizootics of the entomogenous fungus Nomuraea 
rileyi (Farlow) Samson. Gainesville : University of Florida, 1977. 68p. M.Sc. Thesis.

MOSCARDI, F. Utilização de Baculovirus anticarsia para o controle da lagarta da soja, Anticarsia gemmatalis. Londrina: Embrapa-CNPSo, 1983.21p. (Embrapa-CNPSo. Comunicado Técnico, 23).

SHEPHERD, R.F.; OTVOS, I.S.; CHORNEY, R.J.; CUNNINGHAM, J.C. Pest management of Douglas-fir tussock moth (Lepidoptera: Lymantriidae): prevention of an outbreak through early treatment with a nuclear polyhedrosis virus by ground and air applications. Canadian Entomologist, Otawa, v.116, p.1533-1542, 1984.

STELZER, M.J.; NEISESS, J.; CUNNINGHAM, J.C.; McPHEE, J.R. Field evaluation of baculovirus stocks against Douglas-fir tussock moth in British Columbia. Journal of Economic Entomology, Lanham, v.70, n.2, p.243-246, 1977
STELZER, M.J.; NEISESS, J.; THOMPSON, C.G. Aerial applications of a nucleopolyhedrosis virus and Bacillus thuringiensis against the Douglas-fir tussock moth. Journal of Economic Entomology, Lanham, v.68, n.2, p.269-272, 1975.

THOMPSON, C.G.; STEINHAUS, E.A. Further tests using a polyhedrosis virus to control the alfafa caterpillar. Hilgardia, Berkeley, v.19, n.14, p.411$445,1950$.

WOLLAM, J.D.; YENDOL, W.G.; LEWIS, F.B Evaluation of aerially-applied nuclear polyhedrosis virus for suppression of the gypsy moth, Lymantria dispar L. Broomall : USDA-Forest Service, 1978. 8p. (Research Paper, NE-396).

YENDOL, W.G.; HEDLUND, R.C.; LEWIS, F.B. Field investigation of a baculovirus of the gypsy moth. Journal of Economic Entomology, Lanham, v.70, n.5, p.598-602, 1977. 